\title{
Primary Care Physicians' Use of an Informed Decision-Making Process for Prostate Cancer Screening
}

\author{
Robert J. Volk, $P b D^{1}$ \\ Suzanne K. Linder, $P b D^{1}$ \\ Michael A. Kallen, $\mathrm{PbD}, \mathrm{MPH}^{2}$ \\ James M. Galliber, $P b D^{3,4}$ \\ Mindy S. Spano \\ Patricia Dolan Mullen, DrPH \\ Stephen J. Spann, MD, MBA ${ }^{6}$
}

'Department of General Internal Medicine, The University of Texas MD Anderson Cancer Center, Houston, Texas

${ }^{2}$ Department of Medical Social Sciences, Feinberg School of Medicine, Northwestern University, Chicago, Illinois

${ }^{3}$ American Academy of Family Physicians National Research Network; Department of Sociology, University of Missouri-Kansas City, Kansas City, Missouri

${ }^{4}$ Department of Family Medicine, University of Colorado Health Sciences Center at Denver, Denver, Colorado

${ }^{5}$ Center for Health Promotion and Prevention Research, The University of Texas School of Public Health, Houston, Texas

${ }^{6}$ Department of Family and Community Medicine, Baylor College of Medicine, Houston, Texas

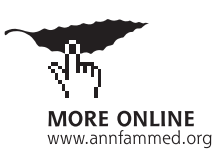

Conflicts of interest: authors report none.

\section{CORRESPONDING AUTHOR}

Robert J. Volk, PhD

Department of General Internal Medicine The University of Texas MD Anderson

Cancer Center

1515 Holcombe Blvd, Unit 1465

Houston, TX 77030

bvolk@mdanderson.org

\begin{abstract}
PURPOSE Leading professional organizations acknowledge the importance of an informed decision-making process for prostate cancer screening. We describe primary care physicians' reports of their prescreening discussions about the potential harms and benefits of prostate cancer screening.
\end{abstract}

METHODS Members of the American Academy of Family Physicians National Research Network responded to a survey that included (1) an indicator of practice styles related to discussing harms and benefits of prostate-specific antigen testing and providing a screening recommendation or letting patients decide, and (2) indicators reflecting physicians' beliefs about prostate cancer screening. The survey was conducted between July 2007 and January 2008.

RESULTS Of 426 physicians 246 (57.7\%) completed the survey questionnaire. Compared with physicians who ordered screening without discussion (24.3\%), physicians who discussed harms and benefits with patients and then let them decide (47.7\%) were more likely to endorse beliefs that scientific evidence does not support screening, that patients should be told about the lack of evidence, and that patients have a right to know the limitations of screening; they were also less likely to endorse the belief that there was no need to educate patients because they wanted to be screened. Concerns about medicolegal risk associated with not screening were more common among physicians who discussed the harms and benefits and recommended screening than among physicians who discussed screening and let their patients decide.

CONCLUSIONS Much of the variability in physicians' use of an informed decisionmaking process can be attributed to beliefs about screening. Concerns about medicolegal risk remain an important barrier for shared decision making.

Ann Fam Med 2013;67-74. doi:10.1370/afm.1445.

\section{INTRODUCTION}

7 he US Preventive Services Task Force recently updated its recommendation about screening for prostate cancer to a D recommendation (the harms of screening for prostate cancer based on prostate-specific antigen [PSA] outweigh the benefits) while acknowledging that men will continue to request screening and physicians should engage their patients in making an informed choice. ${ }^{1}$ The updated 2010 American Cancer Society guideline is more specific: asymptomatic men with at least a 10-year life expectancy should have an opportunity to make an informed decision with their clinician about prostate cancer screening, and screening should not occur without an informed decision-making process whereby the potential uncertainties, risks, and potential benefits are considered. ${ }^{2}$ The latter recommendation in particular presents a challenge for primary care physicians within the context of the many competing demands in clinical practice. ${ }^{3,4}$ Although most primary care physicians 
screen for prostate cancer, ${ }^{5}$ little is known about their use of prescreening discussions of the risks and benefits of screening ${ }^{6}$; this knowledge is a key component of an informed decision-making process. ${ }^{7-9}$

Using telephone focus groups, Purvis Cooper et $\mathrm{al}^{10}$ explored the practice styles of primary care physicians regarding PSA testing and identified 2 practice patterns: routine and nonroutine screening. Most physicians, more than $80 \%$, were routine screeners, automatically ordering PSA tests for men aged 50 years and older with a 10-year life expectancy, without discussing the potential harms and benefits of testing. For routine screeners, this practice pattern was supported by personal and professional experience related to PSA testing, perceived patient expectation to be screened, a belief in scientific evidence showing benefit from PSA testing, community norms favoring screening, awareness of American Cancer Society guidelines, belief that PSA testing is part of comprehensive medical care, and concerns about malpractice for not ordering the test. In contrast, one-fifth of the physicians were described as nonroutine screeners, who did not automatically order PSA testing for their patients. Regardless of the practice pattern, all the physicians noted that they ultimately screened most of their eligible patients for prostate cancer. ${ }^{10}$

The current study examines the use of prescreening discussions regarding the potential benefits and harms of prostate cancer screening by physicians in a large, national primary care research network. It further explores the role of physicians' beliefs about the efficacy of prostate cancer screening and contextual factors related to whether they discuss these harms and benefits.

\section{METHODS}

\section{Survey Participants}

Study participants were physician members of the American Academy of Family Physicians National Research Network (AAFP NRN). Trainees were excluded. Established in 1999, the network is a voluntary research association of primary care clinicians who collaborate on studies to describe and improve primary care practice. Comparisons show that AAFP NRN members are similar to the broader AAFP membership on clinical practice variables, but they differ on percentage of time spent in direct patient care (lower among NRN members). ${ }^{11}$

\section{Survey Instrument}

We used a single-item indicator from a previous study by our group ${ }^{12}$ to classify responding AAFP NRN physician-members on the basis of their self-reported approach to prostate cancer screening for age-appropriate men with no other risk factors. The 5 approaches were as follows: (1) order the PSA test without discussing the potential harms and benefits (screen without discussion); (2) discuss the harms and benefits and then recommend the test (discuss, recommend screening), (3) discuss the harms and benefits and then let the patient decide (discuss, let patient decide); (4) discuss the harms and benefits and then recommend against the test (discuss, recommend against); and (5) neither discuss the harms and benefits nor order the test (don't discuss or recommend). An "other" category was also included. We had previously determined that the practice style indicator had good criterion-related validity against reported prostate cancer-screening rates. ${ }^{12}$

We then drafted statements espousing prostate cancer-screening-related beliefs to reflect the primary and secondary themes identified by Purvis Cooper et $\mathrm{al}^{10}$ and other themes found in the literature. A 5-point Likert scale ranging from 1 (strongly disagree) to 5 (strongly agree) was used for each indicator. The questionnaire was assessed for overall layout, flow, clarity, and time to administer. Redundant indicators were combined, and poorly worded indicators were dropped. A core set of 17 belief indicators was retained for the finalized survey (see Suplemental Appendix, available at http://annfammed.org/ content/11/1/67/suppl/DC1).

Information on the number of years in practice, sex, and clinical practice type (academically affiliated) for each responding physician was obtained from the NRN membership survey conducted by the AAFP.

\section{Data Collection}

Data collection was launched in July 2007 with the final reminder mailed in January 2008. We used a 2-pronged strategy for data collection: e-mail and postal mail. If an e-mail address was available, an invitation was e-mailed to the member from the AAFP NRN research office that contained an electronic link to the online survey. The link uniquely identified each member for tracking purposes. Two e-mail reminders were sent at 3 -week intervals to nonrespondents. The second strategy targeted members without e-mail addresses, whose e-mail invitation was returned undeliverable, or who did not complete the online version. Letters of invitation from the network director were posted to these members along with a copy of the questionnaire and a self-addressed postage-paid return envelope. One reminder letter with the questionnaire and a return envelope was sent to nonrespondents. By participating in the study (returning the mailed questionnaire or answering questions online) the physicians consented to the study. This study was reviewed and 
approved without restrictions by the AAFP and Baylor College of Medicine institutional review boards.

\section{Statistical Analysis}

Two coding schemes were used in our analysis of the physicians' responses regarding the belief indicators on prostate cancer-screening practices. The first was the 5 -point Likert scale, ranging from 1 (strongly disagree) to 5 (strongly agree). The second was an either-or coding system: Likert scale responses 1, 2, and 3 were coded as not endorsing the belief; responses 4 and 5 were coded as endorsing the belief. All belief indicator responses were retained in their original direction and orientation and were not reverse coded to create uniform indicator interpretations as, for example, supportive of or antagonistic to a particular screening practice style.

Bivariate statistics in the form of $\chi^{2}$ or Fisher exact tests were calculated between the practice style indicator, physician characteristics, and each belief indicator. Physician characteristics and belief indicators displaying a relationship with practice style $(P<10)$ were retained in multivariate, multinomial, logistic regression modeling.

Multivariate, multinomial, logistic regression modeling was conducted using practice style as each model's dependent variable and the belief indicators as the primary independent variables. The physician characteristic variables of sex and years in medical practice, as well as academically affiliated practice, were treated as control variables and retained in all models tested. Models were then configured and tested after omitting, one at a time, belief indicators with nonsignificant effects in relation to physician prostate cancer-screening practice style.

Models were assessed in 3 ways for overall adequacy of fit. A $\chi^{2}$-based -2 log-likelihood test was conducted to compare a model estimated to a null model (intercept only) $P<.05$ indicated adequate model prediction. Nominal group classification accuracy was also assessed. Finally, using Nagelkerke's pseudo $R^{2}$ statistic, an estimate of the proportion of variance explained by a model was obtained. Final models provided odds ratio estimates per belief indicator; the preselected referent was the physicians' group reporting a practice style of discuss, let patient decide.

\section{RESULTS}

\section{Study Flow and Population}

Our 2-pronged (e-mail and postal mail) sampling strategy resulted in an overall participation rate of $57.7 \%$ (246 of 426 members; Figure 1). About $43 \%$ of questionnaires were completed online, $57 \%$ were completed and returned by mail. Nearly one-half of the respondents to the online survey were from academically affiliated practices compared with about one-third of respondents to the mailed survey $(P=.037)$. Physicians in our study had been in practice for a slightly longer period of time but were otherwise similar to physicianmembers responding to the NRN membership survey (Table 1).

\section{Physicians' Prostate Cancer-Screening Practice Styles}

Three physicians did not respond to questions about their practice style for prostate cancer screening, leaving 243 questionnaires for further analysis. Nearly one-half of the 243 physicians discussed screening and let their patients decide about testing, almost one-fourth discussed and recommended testing, and another one-fourth ordered the test without discus-

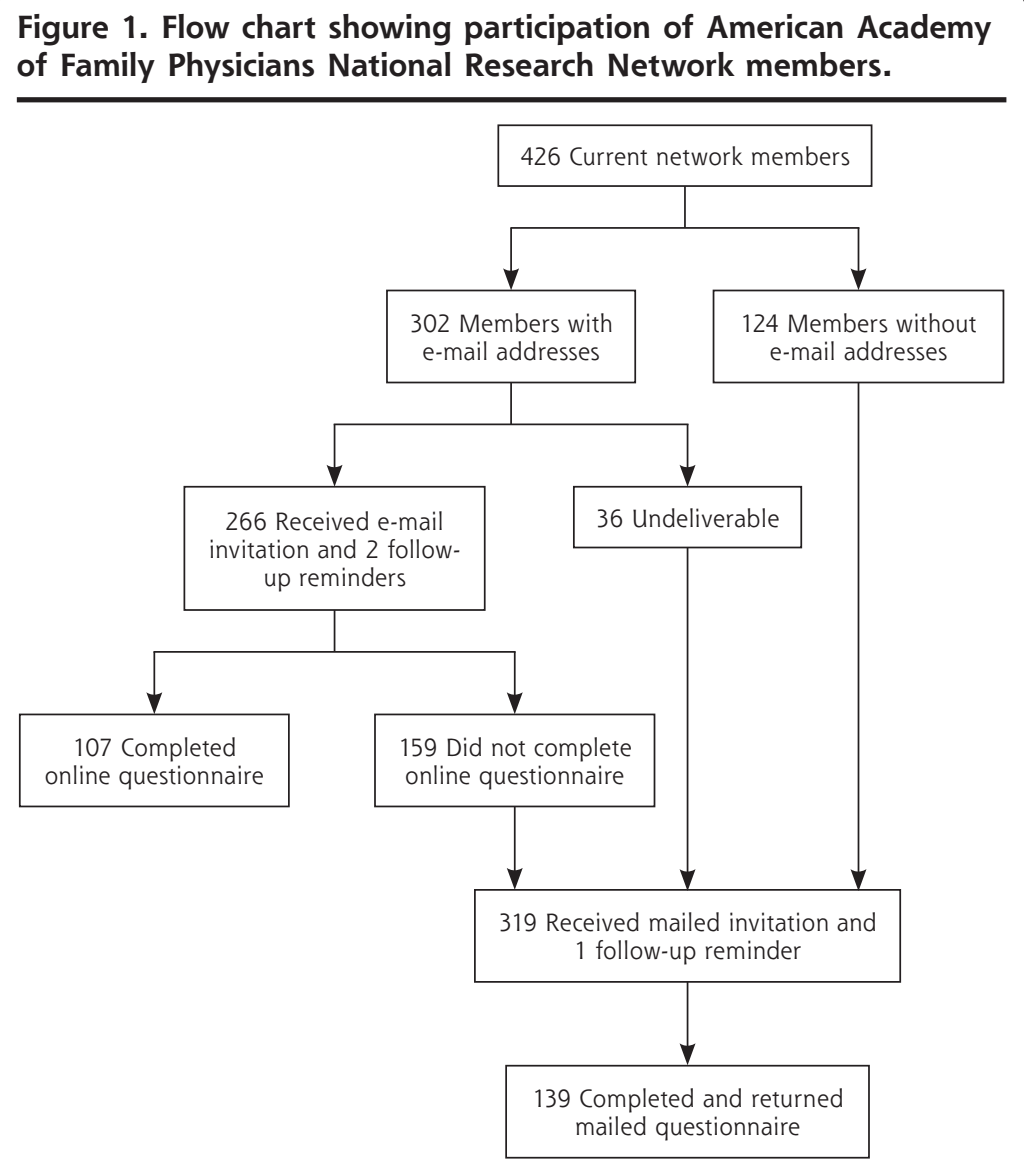

ANNALS OF FAMILY MEDICINE + WWW.ANNFAMMED.ORG + VOL. 11, NO. 1 + JANUARY/FEBRUARY 2013 
Table 1. Characteristics of Participating Physician Members

\begin{tabular}{|c|c|c|c|c|}
\hline \multirow[b]{2}{*}{ Characteristic } & \multirow{2}{*}{$\begin{array}{c}\text { Membership } \\
\text { Survey } \\
(n=209)^{a}\end{array}$} & \multicolumn{3}{|c|}{$\begin{array}{l}\text { Study Sample Survey } \\
\qquad(\mathrm{N}=246)\end{array}$} \\
\hline & & $\begin{array}{c}\text { Online } \\
(n=107)\end{array}$ & $\begin{array}{c}\text { Mailed } \\
(n=139)\end{array}$ & $\begin{array}{c}P \\
\text { Value }^{b}\end{array}$ \\
\hline Years in practice, mean (SD) ${ }^{c}$ & $16.4(8.5)$ & $19.4(8.6)$ & $19.4(9.1)$ & .991 \\
\hline Sex, male, $\%(n)^{d}$ & $71.3(149)$ & $74.3(78)$ & $69.4(93)$ & .406 \\
\hline Academically affiliated practice, \% (n) & $37.3(78)$ & $48.4(46)$ & $34.8(48)$ & .037 \\
\hline \multicolumn{5}{|c|}{$\begin{array}{l}\text { a The American Academy of Family Physicians National Research Network membership survey is not com- } \\
\text { pleted by all member physicians. }\end{array}$} \\
\hline
\end{tabular}

\section{Figure 2. Practice styles for prostate cancer screening among American Academy of Family Physicians National Research Network physician members $(n=243)$.}

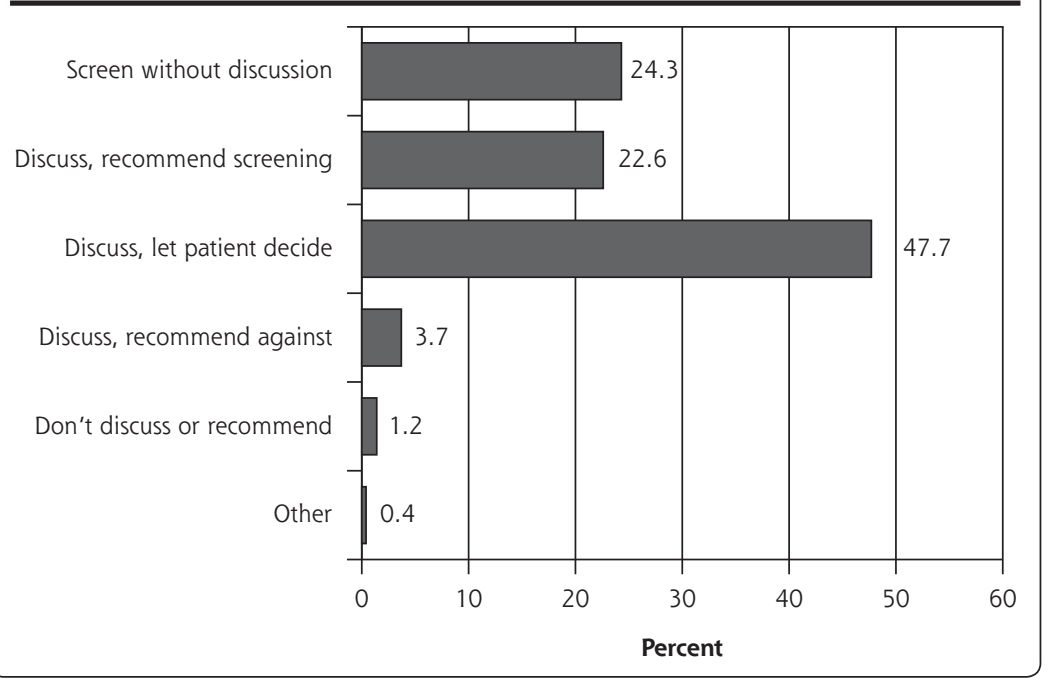

distribution of sex did not differ significantly across the practice styles. Compared with physicians who discussed the potential harms and benefits of prostate cancer screening and either recommended the test or let the patient decide, physicians who screen patients without discussion were less likely to practice at an academically affiliated site. Fifteen of the 17 belief indicators were significantly associated with practice style (Table 2). The 2 nonsignificant belief indicators were in regard to professional experience with prostate cancer and personal experience with the disease.

\section{Results From Multinomial, Logistic Regression Modeling} Physicians endorsing discuss, let patient decide were compared with physicians who endorsed screen without discussion and then physicians who endorsed discuss, recommend screening. The final multinomial logistic regression model included 7 belief indicators, each of which had a significant independent effect (Table 3). The effects were adjusted for years in practice, sex of physician, and clinical practice type (academically affiliated practice). The model had favorable fit characteristics: adequate model predic-

sion (Figure 2). The remaining 5\% of respondents discussed and recommended against the PSA test, neither discussed it nor recommended it, or selected the "other" response option.

For subsequent analysis, we retained only the 3 most reported practice styles ( $\mathrm{n}=230$ physicians): discuss, recommend screening; discuss, let patient decide and screen without discussion.

\section{Beliefs About Screening and Physician Practice Styles}

The mean length of time in practice did not differ significantly across the 3 most common practice styles: screen without discussion, 21.4 years $(\mathrm{SD}=7.3$ years); discuss, then recommend, 19.5 years ( $\mathrm{SD}=11.3$ years); discuss, let patient decide, 19.3 years $(\mathrm{SD}=8.5$ years); $P=.148$ ). The distributions of other physician characteristics and responses to the belief indicators across the 3 selected practice styles are shown in Table 2 . The tion compared with the null model $(P<.001)$, adequate group classification (across-group average was 76.6\%), and a high proportion of variance explained by the model (Nagelkerke pseudo $R^{2}=0.67$ ).

The style-specific significance of the belief indicators varied by which practice styles were compared (Table 3). Compared with physicians who ordered PSA testing without discussion, physicians who reported discussing the harms and benefits and then letting their patients decide about screening were more likely to endorse beliefs that scientific evidence does not support routine screening, that patients should be told about the lack of evidence, and that patients have a right to know the implications of screening. These physicians were also less likely to endorse the belief that there was no need to educate patients because the patients want to be screened. On the other hand, compared with physicians who discussed and then recommended screening, physicians who discussed and let their patients decide 
Table 2. Distribution of Physician Characteristics and Responses to Screening Beliefs Indicators, by the 3 Most Common Clinical Practice Styles for Prostate Cancer Screening

\begin{tabular}{|c|c|c|c|c|c|}
\hline \multirow[b]{2}{*}{ Variable } & \multirow[b]{2}{*}{$\begin{array}{l}\text { Score for Beliefs } \\
\text { Indicators, } \\
\text { Mean (SD) }\end{array}$} & \multicolumn{3}{|c|}{$\begin{array}{l}\text { Practice Style and Belief } \\
\text { Endorsement, } \%^{a}\end{array}$} & \multirow[b]{2}{*}{$\begin{array}{c}P \\
\text { Value }\end{array}$} \\
\hline & & $\begin{array}{c}\text { Screen } \\
\text { Without } \\
\text { Discussion } \\
(n=59)\end{array}$ & $\begin{array}{c}\text { Discuss, } \\
\text { Recommend } \\
\text { Screening } \\
(n=55)\end{array}$ & $\begin{array}{l}\text { Discuss, } \\
\text { Let Patient } \\
\text { Decide } \\
(n=116)\end{array}$ & \\
\hline \multicolumn{6}{|l|}{ Physician characteristics } \\
\hline Sex, male & & 75.9 & 73.6 & 68.7 & .577 \\
\hline Academically affiliated practice & & 3.6 & 41.5 & 56.6 & $<.001$ \\
\hline \multicolumn{6}{|l|}{ Beliefs indicators } \\
\hline \multicolumn{6}{|l|}{ Screening/treatment efficacy } \\
\hline $\begin{array}{l}\text { The benefits of prostate cancer screening outweigh } \\
\text { the risks }\end{array}$ & $3.40(1.00)$ & 76.3 & 69.1 & 16.5 & $<.001$ \\
\hline $\begin{array}{l}\text { I have wondered if treatment for prostate cancer is } \\
\text { worth it for some patients }\end{array}$ & $3.65(0.97)$ & 50.8 & 64.8 & 87.9 & $<.001$ \\
\hline \multicolumn{6}{|l|}{ Scientific evidence } \\
\hline $\begin{array}{l}\text { There is clear evidence that prostate cancer screening } \\
\text { saves lives }\end{array}$ & $2.52(0.99)$ & 30.5 & 30.9 & 1.7 & $<.001$ \\
\hline $\begin{array}{l}\text { My clinical experience is more important than } \\
\text { research studies in how I handle screening }\end{array}$ & $2.96(1.21)$ & 25.4 & 25.9 & 3.4 & $<.001$ \\
\hline $\begin{array}{l}\text { The scientific evidence does not support routine } \\
\text { screening for prostate cancer }\end{array}$ & $3.31(0.88)$ & 20.3 & 23.6 & 71.6 & $<.001$ \\
\hline \multicolumn{6}{|l|}{ Evidence-based medicine orientation } \\
\hline $\begin{array}{l}\text { I would describe myself as someone who practices } \\
\text { evidence-based medicine }\end{array}$ & $3.97(0.53)$ & 71.2 & 87.3 & 90.5 & .003 \\
\hline \multicolumn{6}{|l|}{ Professional experience } \\
\hline $\begin{array}{l}\text { I have lost patients to prostate cancer who might have } \\
\text { been saved if they had been screened with PSA }\end{array}$ & $2.51(1.08)$ & 27.6 & 27.8 & 16.4 & .119 \\
\hline \multicolumn{6}{|l|}{ Personal experience } \\
\hline $\begin{array}{l}\text { I have lost close family members or friends to pros- } \\
\text { tate cancer }\end{array}$ & $2.34(1.29)$ & 28.8 & 25.9 & 22.4 & .638 \\
\hline \multicolumn{6}{|l|}{ Prescreening discussion } \\
\hline $\begin{array}{l}\text { Patients should be told that it has yet to be proven } \\
\text { that prostate cancer screening saves lives }\end{array}$ & $3.82(0.95)$ & 35.6 & 61.8 & 90.5 & $<.001$ \\
\hline \multicolumn{6}{|l|}{ Patients' rights } \\
\hline $\begin{array}{l}\text { Patients have a right to know the implications of pros- } \\
\text { tate cancer screening before they are screened }\end{array}$ & $4.20(0.70)$ & 52.5 & 92.7 & 98.3 & $<.001$ \\
\hline \multicolumn{6}{|l|}{ Patients' expectations } \\
\hline $\begin{array}{l}\text { There is no need to educate patients about prostate } \\
\text { cancer screening because in general they want to } \\
\text { be screened }\end{array}$ & $2.42(1.11)$ & 54.2 & 22.2 & 6.9 & $<.001$ \\
\hline My patients frequently request the PSA test & $3.87(0.79)$ & 83.1 & 73.6 & 63.8 & .026 \\
\hline \multicolumn{6}{|l|}{ Patient anxiety } \\
\hline $\begin{array}{l}\text { Discussing harms and benefits of prostate cancer } \\
\text { screening causes unnecessary anxiety in my patients }\end{array}$ & $2.62(0.96)$ & 32.2 & 25.5 & 14.8 & .024 \\
\hline \multicolumn{6}{|l|}{ Regret } \\
\hline $\begin{array}{l}\text { There have been times when I have regretted order- } \\
\text { ing a PSA test for a patient }\end{array}$ & $2.96(1.21)$ & 25.4 & 39.6 & 56.9 & $<.001$ \\
\hline \multicolumn{6}{|l|}{ Malpractice concerns } \\
\hline $\begin{array}{l}\text { Not ordering a PSA test puts a physician at risk for } \\
\text { malpractice liability }\end{array}$ & $3.82(0.90)$ & 76.3 & 87.3 & 63.8 & .004 \\
\hline \multicolumn{6}{|l|}{ Community standards } \\
\hline $\begin{array}{l}\text { Prostate cancer screening is a standard of care in my } \\
\text { community }\end{array}$ & $4.02(0.75)$ & 94.8 & 90.9 & 64.7 & $<.001$ \\
\hline \multicolumn{6}{|l|}{ Time barriers } \\
\hline $\begin{array}{l}\text { I do not have time to discuss the harms and benefits } \\
\text { of prostate cancer screening with my patients }\end{array}$ & $2.67(1.06)$ & 42.4 & 18.2 & 22.4 & .005 \\
\hline
\end{tabular}


Table 3. Multinomial Logistic Regression Analysis of Screening Beliefs Indicators Predicting Clinical Practice Style for Prostate Cancer Screening

\begin{tabular}{|c|c|c|c|c|}
\hline \multirow[b]{2}{*}{ Beliefs Indicators ${ }^{a}$} & \multicolumn{2}{|c|}{$\begin{array}{l}\text { Discuss, Let Patient } \\
\text { Decide vs Screen } \\
\text { Without Discussion }\end{array}$} & \multicolumn{2}{|c|}{$\begin{array}{l}\text { Discuss, Let Patient } \\
\text { Decide vs Discuss, } \\
\text { Recommend Screening }\end{array}$} \\
\hline & $\mathrm{OR}^{\mathrm{b}}$ & $P$ Value & $\mathbf{O R}^{\mathbf{b}}$ & $P$ Value \\
\hline The benefits of prostate cancer screening outweigh the risks & - & - & 0.269 & .009 \\
\hline There is clear evidence that prostate cancer screening saves lives & - & - & 0.092 & .012 \\
\hline $\begin{array}{l}\text { The scientific evidence does not support routine screening for prostate } \\
\text { cancer }\end{array}$ & 3.628 & .046 & 2.713 & .040 \\
\hline $\begin{array}{l}\text { Patients should be told that it has yet to be proved that prostate can- } \\
\text { cer screening saves }\end{array}$ & 6.073 & .003 & - & - \\
\hline $\begin{array}{l}\text { Patients have a right to know the implications of prostate cancer } \\
\text { screening before they are screened }\end{array}$ & 10.535 & .015 & - & - \\
\hline $\begin{array}{l}\text { There is no need to educate patients about prostate cancer screening } \\
\text { because in general they want to be screened }\end{array}$ & 0.122 & .001 & - & - \\
\hline Not ordering a PSA test puts a physician at risk for malpractice liability & - & - & 0.271 & .025 \\
\hline \multicolumn{5}{|l|}{ OR $=$ odds ratio. } \\
\hline \multicolumn{5}{|c|}{$\begin{array}{l}\text { a Belief indicators are scored as endorsed (ie, agree or strongly agree) or not endorsed (neutral, disagree, or strongly disagree). } \\
\text { b Interpreted as the ratio of the odds of endorsing a belief indicator among physicians who reported a prostate cancer screening practice style of discuss, let patient } \\
\text { decide vs the odds of endorsing the same belief indicator among physicians who reported the practice style of screen without discussion (first column) or discuss, rec- } \\
\text { ommend screening (second column). }\end{array}$} \\
\hline
\end{tabular}

were more likely to endorse the idea that scientific evidence does not support screening; they were also less likely to endorse the beliefs that not screening puts a physician at medicolegal risk, that the benefits of screening outweighed the risks, and that the evidence clearly indicates that screening saves lives.

\section{DISCUSSION}

In this study of physician members of the AAFP NRN, we observed considerable variability in self-reported approaches to engaging patients in discussions about the harms and benefits of prostate cancer screening and how decisions are made. Many physicians appear to order PSA testing for asymptomatic men within the recommended age range for screening without first discussing the potential harms and benefits of testing with their patients.

There is another, larger, group of physicians who report engaging patients who are candidates for prostate cancer screening in discussions about the harms and benefits, but these physicians differed in the degree to which they encourage patient autonomy in making the decision. Some of the physicians recommend screening, and others let the patient decide. This distinction is important, as it suggests that some physicians, while attempting to use an informed decision-making process, may actually be using an informed consent process involving a discussion of risks but still wanting their patients screened. Whether these physicians consider their practice style consistent with screening guidelines would be an interesting question to explore.

Physicians who reported engaging patients in prescreening discussions of the harms and benefits of PSA testing and allowing their patients to decide differed from physicians who reported other practice styles in several important ways. First, the belief about scientific evidence not supporting routine screening was more likely to be endorsed by the former group than the latter. With the subsequent release of the large European Randomized Study of Screening for Prostate Cancer (ERSPC), ${ }^{13}$ US Prostate, Lung, Colorectal, and Ovarian (PLCO) Cancer Screening Trial results, ${ }_{1}^{14}$ and several recent systematic reviews, ${ }^{15,16}$ the belief that scientific evidence does support routine screening may continue to be challenged. Yet, it is unclear whether the trial evidence or changes in guidelines will have a major impact on prostate cancer-screening rates. ${ }^{17,18}$

Second, the beliefs that patients should be told about the lack of evidence supporting screening and that patients have a right to know this information were more often endorsed by the physicians who discuss and let patients decide than by the physicians who order the PSA test outright. Conversely, physicians who ordered the test without discussion were more likely to believe that their patients want testing and that education is not needed. These observations offer an interesting juxtaposition of concerns about patient autonomy and the right to know important medical information and the pragmatic argument that education has no impact on screening preferences. A focus 
on the decision as opposed to the decision-making process appears to distinguish these 2 practice styles.

Finally, there is the provocative finding that physicians who discuss the harms and benefits and recommend the test more often endorsed concerns about the medicolegal risk associated with not screening compared with physicians who discuss and let the patient decide. These concerns have been highlighted by others and appear to have some impact on PSA testing rates. ${ }^{19-21}$

Patient decision aids may be one solution for physicians who believe limited time with a patient is a barrier to the informed decision-making process and for those who have concerns about the medicolegal risks of not routinely screening men. Decision aids used before the clinical encounter may prepare patients for the informed decision-making process and lessen the process burden on the physician. In a study using mock trials, Barry and colleagues ${ }^{22}$ found that almost all jurors agreed that a physician who provides an aid and documents that the patients has reviewed the aid in the medical chart would meet the standard of care. Some legal opinions suggest that a shared decision-making process using decision aids may also help "satisfy the legal requirements of disclosure of risks, benefits, and alternatives," and also establish a higher burden of proof for patients who attempt to claim that they were not adequately informed of risks or alternatives. ${ }^{23}$

Despite a participation rate similar to that from other surveys of the AAFP NRN membership, ${ }^{11}$ our study has several limitations. We do not know how well the reported practice styles related to actual physician-patient interactions and to the use of an informed decision-making process, and we might expect that discussions about prostate cancer screening occur less frequently than physicians reported. ${ }^{24}$ Our study was limited to family physicians, so the applicability of the findings to other clinicians (eg, general internists and nurse practitioners) is not known. Another limitation of the survey was that we did not ask physicians whether they used patient decision aids. Finally, we conducted the survey before the results of the ERSPC ${ }^{14}$ and the US PLCO Cancer Screening Trial ${ }^{13}$ were published in March 2009, which showed minimal mortality benefit from screening (only in the European trial) and raised increasing concerns about overdetection of prostate cancer.

We observed considerable variability in primary care physicians' use of an informed decision-making process for prostate cancer screening. Much of the variability in these practice styles can be attributed to beliefs about screening, and some of these beliefs may be amenable to change. Currently, there are few negative sequelae for physicians who routinely screen patients for prostate cancer. ${ }^{25}$ As the scientific evidence continues to grow regarding the limited benefits of screening with PSA testing and practice guidelines more strongly recommend preference-based decision making, we may expect physicians who do not engage their patients in discussions about the potential harms and benefits of screening to consider changing their practice styles. Efforts to educate physicians about the shared decision-making process should include countering the beliefs that perpetuate routine screening.

\section{To read or post commentaries in response to this article, see it} online at http://www.annfammed.org/content/11/1/67.

Key words: prostatic neoplasms; decision making; physicians, primary care; early detection of cancer

Submitted December 29, 2011; submitted, revised, May 25, 2012; accepted July 17, 2012.

Funding support: This study was supported in part by grants from the Texas Academy of Family Physicians Foundation, the American Academy of Family Physicians Foundation (grant No. G0602PB), and the Centers for Disease Control and Prevention (Cooperative Agreement No. U48 DP000057). Dr Linder was funded through a predoctoral fellowship, University of Texas School of Public Health Cancer Education and Career Development Program, National Cancer Institute/NIH Grant R25-CA-57712. Dr Linder was also a postdoctoral fellow in the Department of General Internal Medicine, The University of Texas MD Anderson Cancer Center in Houston, Texas.

Disclaimer: The sponsors had no role in the design and conduct of the study; in the collection management, analysis, and interpretation of the data; or in the preparation, review, or approval of the manuscript. The content is solely the responsibility of the authors and does not necessarily represent the official views of the National Cancer Institute or the National Institutes of Health.

Previous presentation: Portions of this study were presented at the 36th Annual Meeting of the North American Primary Care Research Group, San Juan, Puerto Rico, November 16, 2008.

Acknowledgments: We wish to acknowledge Elizabeth Hess for her editorial contributions to this manuscript.

\section{References}

1. Moyer VA. Screening for Prostate Cancer: U.S. Preventive Services Task Force Recommendation Statement. Ann Intern Med. 2012;157 (2):120-134

2. Wolf AM, Wender RC, Etzioni RB, et al; American Cancer Society Prostate Cancer Advisory Committee. American Cancer Society guideline for the early detection of prostate cancer: update 2010. CA Cancer J Clin. 2010;60(2):70-98.

3. Spann SJ. Prostate cancer screening-what's a physician to do? Am Fam Physician 1997;56(6):1563-4, 67-8.

4. Yarnall KS, Pollak KI, Østbye T, Krause KM, Michener JL. Primary care: is there enough time for prevention? Am J Public Health. 2003; 93(4):635-641.

5. Dunn AS, Shridharani KV, Lou W, Bernstein J, Horowitz CR. Physician-patient discussions of controversial cancer screening tests. Am J Prev Med. 2001;20(2):130-134. 
6. Hall IJ, Taylor YJ, Ross LE, Richardson LC, Richards TB, Rim SH. Discussions about prostate cancer screening between U.S. primary care physicians and their patients. J Gen Intern Med. 2011;26(10):1098-1104.

7. Briss P, Rimer B, Reilley B, et al; Task Force on Community Preventive Services. Promoting informed decisions about cancer screening in communities and healthcare systems. Am J Prev Med. 2004; 26(1):67-80.

8. Guerra CE, Jacobs SE, Holmes JH, Shea JA. Are physicians discussing prostate cancer screening with their patients and why or why not? A pilot study. J Gen Intern Med. 2007;22(7):901-907.

9. McCormack L, Williams-Piehota P, Bann C. Behind closed doors: what happens when patients and providers talk about prostate-specific antigen screening? Survey of the effects of a community-based intervention. Patient. 2009;2(3):191-201.

10. Purvis Cooper C, Merritt TL, Ross LE, John LV, Jorgensen CM. To screen or not to screen, when clinical guidelines disagree: primary care physicians' use of the PSA test. Prev Med. 2004;38(2):182-191.

11. Galliher JM, Bonham AJ, Dickinson LM, Staton EW, Pace WD. Representativeness of PBRN physician practice patterns and related beliefs: the case of the AAFP National Research Network. Ann Fam Med. 2009;7(6):547-554.

12. Linder SK, Hawley ST, Cooper CP, Scholl LE, Jibaja-Weiss M, Volk RJ. Primary care physicians' reported use of pre-screening discussions for prostate cancer screening: a cross-sectional survey. BMC Fam Pract. 2009;10:19.

13. Andriole GL, Crawford ED, Grubb RL III, et al; PLCO Project Team. Mortality results from a randomized prostate-cancer screening trial. N Engl J Med. 2009;360(13):1310-1319.

14. Schröder FH, Hugosson J, Roobol MJ, et al; ERSPC Investigators Screening and prostate-cancer mortality in a randomized European study. N Engl J Med. 2009;360(13):1320-1328.

15. Chou R, Croswell JM, Dana T, et al. Screening for prostate cancer: a review of the evidence for the U.S. Preventive Services Task Force. Ann Intern Med. 2011;155(11):762-771.
16. Ilic D, O'Connor D, Green S, Wilt TJ. Screening for prostate cancer: an updated Cochrane systematic review. BJU Int. 2011;107(6):882-891.

17. Zeliadt SB, Hoffman RM, Etzioni R, Gore JL, Kessler LG, Lin DW. Influence of publication of US and European prostate cancer screening trials on PSA testing practices. J Natl Cancer Inst. 2011;103(6): 520-523.

18. Pollack CE, Noronha G, Green GE, Bhavsar NA, Carter HB. Primary care providers' response to the US Preventive Services Task Force draft recommendations on screening for prostate cancer. Arch Intern Med. 2012;172(8):668-670.

19. Merenstein D. A piece of my mind. Winners and losers. JAMA. 2004;291(1):15-16.

20. Foundation for Informed Medical Decision Making. Informing and involving patients in medical decisions: the primary care physicians' perspective, February 2009. Available at: http://www.allhealth.org/ briefingmaterials/PhysicianPerspective-1942.pdf. Accessed Dec 28, 2011.

21. Krist AH, Woolf SH, Johnson RE. How physicians approach prostate cancer screening before and after losing a lawsuit. Ann Fam Med. 2007;5(2):120-125.

22. Barry MJ, Wescott PH, Reifler EJ, Chang Y, Moulton BW. Reactions of potential jurors to a hypothetical malpractice suit: alleging failure to perform a prostate-specific antigen test. J Law Med Ethics 2008;36(2):396-402, 214

23. Moulton $B$, King JS. Aligning ethics with medical decision-making: the quest for informed patient choice. J Law Med Ethics. 2010;38(1): 85-97.

24. Hoffman RM, Couper MP, Zikmund-Fisher BJ, et al. Prostate cancer screening decisions: results from the National Survey of Medical Decisions (DECISIONS study). Arch Intern Med. 2009;169(17): 1611-1618.

25. Ransohoff DF, McNaughton Collins M, Fowler FJ. Why is prostate cancer screening so common when the evidence is so uncertain? A system without negative feedback. Am J Med. 2002;113(8):663-667. 